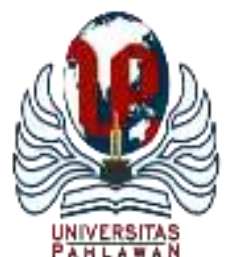

\title{
JURNALBASICEDU
}

Volume 6 Nomor 1 Tahun 2022 Halaman 978 - 986

Research \& Learningin Elementary Education https://jbasic.org/index.php/basicedu

\section{Pengembangan Model Pembelajaran Ciri Khusus Hewan Menggunakan PBL dan PjBL Berbantuan Media Black Box ARVR}

\author{
Ahmad Irfan Barokah $^{1 凶}$, Hari Wahyono ${ }^{2}$, Sri Listyarini ${ }^{3}$ \\ Universitas Terbuka, Indonesia ${ }^{1,3}$, Universitas Tidar, Indonesia ${ }^{2}$ \\ E-mail: $\underline{\text { irfanahmadbarokah@gmail.com }}{ }^{1}$, hariwahyono@ untidar.ac.id $^{2}, \underline{\text { sitia@ecampus.ut.ac.id }}^{3}$
}

\begin{abstract}
Abstrak
Penelitian ini bertujuan untuk membuat dan mengembangkan model pembelajaran ciri khusus hewan di Kelas VI SD seKecamatan Parakan. Model pembelajaran yang dikembangkan adalah memadukan PBL dan PjBL berbantuan Black Box ARVR. Penelitian ini dilaksanakan di SD se-Kecamatan Parakan pada Siswa Kelas VI muatan pelajaran IPA materi Ciri Khusus Hewan. Desain penelitian adalah penelitian pengembangan (Research and Development). Teknik pengumpulan data yang digunakan adalah wawancara dan rubrik. Populasi penelitian ini adalah seluruh Guru dan peserta didik Kelas VI se-Kecamatan Parakan Tahun Ajaran 2019-2020, dengan sampel penelitian 20 Guru kelas VI. Hasil Peneltian ini adalah Model Pembelajaran Ciri Khusus Hewan Menggunakan PBL dan PjBL berbantuan Black Box ARVR (1) mencapai tingkat kelayakan desain 98\% dan kelayakan produk 98\% dengan metode expert judgement, (2) hasil observasi minat Sebanyak 10 kelas (67\%) menyatakan sangat minat, sebanyak 2 kelas (13\%) menyatakan minat, dan sisanya 3 kelas $(20 \%)$ menyatakan cukup minat, (3) terdapat perbedaan hasil belajar peserta didik pada kelas eksperimen yang awalnya sebanyak 15 kelas (100\%) tidak mencapai target menjadi sebanyak 12 peserta didik (80\%) mencapai target pembelajaran. Kesimpulan bahwa Pengembangan Model pembelajaran Ciri Khusus Hewan Menggunakan PBL dan PjBL berbantuan Black Box ARVR dapat menyelesaikan permasalahan pembelajaran yang terjadi pada Kelas VI se-Kecamatan Parakan.
\end{abstract}

Kata Kunci: Black Box ARVR, PBL, PjBL, pembelajaran

\begin{abstract}
This study aims to create and develop a learning model for special animal characteristics in Class VI SD in Parakan District. The learning model developed is to combine PBL and PjBL assisted by Black Box ARVR. This research was carried out in elementary schools throughout Parakan Sub-district for Class VI students with the content of science lessons for Animal Special Characteristics. The research design is research and development.. Data collection techniques used are interviews and rubrics. The population of this study was all teachers and students of Class VI in Parakan Sub-district for the 2019-2020 Academic Year, with a research sample of 20 Class VI teachers. The results of this research are the Animal Characteristics Learning Model Using PBL and PjBL assisted by Black Box ARVR (1) achieving a design feasibility level of $98 \%$ and product feasibility $98 \%$ using the expert judgment method, (2) the results of interest observation A total of 10 classes (67\%) stated very interested, as many as 2 classes (13\%) expressed interest, and the remaining 3 classes (20\%) expressed quite interest, (3) there were differences in student learning outcomes in the experimental class which initially as many as 15 classes (100\%) did not reach the target to become as many as 12 students (80\%) achieved the learning target. The conclusion is that the Development of Animal Characteristics Learning Models using PBL and PjBL assisted by Blackbox ARVR can solve learning problems that occur in Class VI in Parakan sub-district.
\end{abstract}

Keywords: Black Box ARVR, PBL, PjBL, learning

Copyright (c) 2022 Ahmad Irfan Barokah, Hari Wahyono, Sri Listyarini

$\triangle$ Corresponding author :

Email : irfanahmadbarokah@gmail.com

DOI : $\quad$ https://doi.org/10.31004/basicedu.v6i1.1949

ISSN 2580-3735 (Media Cetak)

ISSN 2580-1147 (Media Online) 


\section{PENDAHULUAN}

Kelemahan pendidikan di Indonesia lebih sering terjadi karena kelemahan pada proses pembelajaran yang dilakukan oleh guru-guru (Sutopo, 2019, h. 15). Seperti sikap guru yang otoriter dalam melaksanakan pembelajaran sehingga peserta didik tidak diberi ruang berkreasi, penggunaan metode dan model pembelajaran yang kuno dan kurang menekankan student active learning (Anazifa \& Djukri, 2017). Kelemahan-kelemahan tersebut membuat tujuan pembelajaran yang ditetapkan oleh guru sering tidak menemui hasil yang maksimal. Tujuan pembelajaran yang telah ditetapkan oleh peneliti pada saat mengajar di Kelas VI SDN Mandisari materi Ciri Khusus Hewan juga belum tercapai. Berdasar hasil analisis, dari 30 siswa didapat sebanyak 24 peserta didik (80\%) memperoleh nilai di bawah KKM, sisanya 6 peserta didik (20\%) mencapai nilai KKM. Sedangkan nilai rata-rata kelasnya hanya mencapai 58,42 sedangkan nilai KKM sendiri adalah 75. Permasalan pembelajaran yang terjadi kemudian dicari akar permasalahannya bersama rekan sejawat dan Pengawas Sekolah Kecamatan Parakan. Pada tahap ini dilakukan menggunakan wawancara personal setiap guru (Education et al., 2021). Hasil dari wawancara kemudian dilakukan tabulasi untuk menentukan kesimpulan bersama. Dari hasil tabulasi data maka diperoleh kesimpulan bahwa penyebab terjadinya permasalahan pembelajaran adalah penerapan model pembelajaran yang selama ini yang dilakukan oleh guru selama ini masih terkesan kuno dan monoton. Pembelajaran cenderung berpusat pada guru dan dominasi guru dalam pembelajaran masih tinggi (teacher centered learning). Sugiyono (2019, h. 37) menyatakan bahwa seorang guru yang cerdas adalah yang mampu melihat masalah sebagi sebuah potensi. Berangkat dari itu, maka peneliti berusaha mencari formula terbaik untuk mengatasi masalah di dalam pembelajaran. Formula yang ditawarkan oleh peneliti sebagai solusi dari masalah yang ditemukan adalah penerapan model pembelajaran yang inovatif dalam pembelajaran materi Ciri Khusus Hewan.

Peneliti kemudian melakukan pengembangan Model Pembelajaran Problem Based Learning (PBL) dan Project Based Learning (PjBL). Model Pembelajaran PBL memiliki keunggulan dalam penerapannya yaitu terjadinya pembelajaran yang bermakna (meaning full learning). Peserta didik yang belajar menyelesaikan sebuah masalah akan memaksimalkan seluruh pengetahuan yang dimiliki dan mencari tau pengetahuan apa yang harus digunakan. Belajar dengan model PBL akan semakin memiliki makna ketika guru mampu memperluas tingkatan pengetahuan pendidik sampai ke dasar-dasar teori dan konsep. Akan tetapi, PBL juga memiliki kelemahan mendasar yaitu tahapan pemahaman diawal tidak ada dalam PBL, membuat peserta didik yang kurang paham semakin merasa kesulitan memahami makna dari proses pembelajaran (Siagian, 2021). Dengan demikian jika pengetahuan yang dimiliki peserta didik di awal pembelajaran rendah, maka akan berdampak pada proses penyelesaian masalah yang diberikan oleh guru. Oleh karena itu, perlu adanya stimulan agar peserta didik mau mencari sumber belajar yang luas. Stimulan tersebut berupa penerapan PjBL sekaligus dalam pembelajaran. PjBL akan memungkinkan peserta didik secara naluri ingin sekali terlibat dalam perencanaan dan pembuatan proyek(Utia \& Fauzi, 2021). Keinginan ini disebut dengan motivasi yang berasal dari dalam diri peserta didik atau disebut motivasi intrinsik. Namun, PjBL bukan tanpa kelemahan. Penerapan PjBL untuk anak yang sulit mencari sumber informasi, maka mereka akan kesulitan mencari solusi atas masalah yang didapati (Siswa \& Ammy, 2021).

Dari keterangan tersebut, maka peneliti berinisiatif memadukan model pembelajaran PBL dan PjBL dengan bantuan Media inovatif dan interaktif. Media yang dimaksud bernama " "Black Box" ARVR". Peneliti memiliki keyakinan bahwa Pengembangan Model Pembelajaran Ciri Khusus Hewan Menggunakan PBL dan PjBL Berbantuan Media "Black Box" ARVR" mampu menjadi solusi terbaik untuk menyelesaikan permasalahan pembelajaran yang terjadi di Kelas VI SD Mandisari, Kecamatan Parakan, Kabupaten Temanggung. Dari hasil studi literasi terhadap penelitian terdahulu yang relevan, diperoleh perbedaan yang sangat signifikan sebagai kebaruan penelitian ini. Kebaruan tersebut adalah bahwa penelitian ini merupakan penelitian yang bertujuan untuk mengembangkan Model Pembelajaran Ciri Khusus Hewan menggunakan 
PBL dan PjBL berbantuan Media Black "Black Box" ARVR. Penelitian ini juga memiliki manfaat secara keilmuan yaitu menghasilkan sebuah teori penggabungan dua model pembelajaran PBL dengan PjBL berbantuan media "Black Box" ARVR Teori yang dikembangkan merupakan teori baru hasil pengembangan teori yang sudah ada. Model integrasi PBL dengan PjBL dilakukan dengan langkah-langkah mengawali proses pembelajaran dengan masalah dan mengakhiri dengan sebuah proyek untuk menyelesaikan masalah tersebut.

Pendapat Sani (2018, h. 19) memberikan pengertian bahwa Problem Based Learning adalah sebuah pembelajaran dengan model pemecahan masalah yang melibatkan peserta didik melalui beberapa tahapan ilmiah sehingga peserta didik memperoleh pengetahuan dari masalah yang disajikan serta dalam satu waktu mampu memecahkan masalah tersebut. Berdasarkan pendapat (Nafiah, Suyanto, \& Yogyakarta, 2014) bahwa pembelajaran Berbasis Proyek (Project Based Learning) adalah model pembelajaran yang berbasis proyek yang menekankan peserta didik harus fokus pada proyek untuk memecahkan sebuah masalah yang akan dipamerkan kepada masyarakat. Pembelajaran dengan model PjBL harus dilaksanakan dengan kurun waktu tertentu karena melibatkan peserta didik untuk merancang proyek, membuat, dan menampilkan kepada masyarakat sebagai solusi sebuah masalah yang nyata (Dolmans, Loyens, Marcq, \& Gijbels, 2016). Berdasarkan pendapat tersebut maka dapat disimpulkan bahwa pembelajaran PBL dan PjBL yang dikembangkan merupakan sebuah teori pembelajaran model pemecahan masalah yang melalui serangkaian kegiatan dengan diawali penyejian masalah dan diakhiri dengan pembuatan proyek untuk menyelesaikan masalah. Sedangkan media "Black Box" ARVR merupakan media yang dikembangkan oleh guru (peneliti) dengan memanfaatkan barang bekas berupa kardus dan berbasis Augmented Reality dan Virtual Reality (ARVR). Media ini berupa kotak hitam berbentuk kubus dengan ukuran $30 \mathrm{~cm}$ yang dilengkapi dengan tiga media di dalamnya. Tiga media tersebut adalah kacamata VR, kartu AR, dan kartu pindai Game Edu. Tujuan penggunaan media tersebut untuk menyampaikan pesan materi pembelajaran secara mendalam dan membantu langkah-langkah pembelajaran yang dikembangkan berjalan sesuai dengan perencanaan.

Kerangka berpikir pada penelitian ini bahwa proses pembelajaran dimulai dengan langkah awal yaitu guru memberi masalah kontekstual kepada peserta didik dengan memanfaatkan media "Black Box" ARVR. Tahap selanjutnya adalah peserta didik mencari dan menemukan ide-ide untuk menyelesaikan permasalahan yang dianalisis pada tahap sebelumnya. Tahap ketiga, peserta didik menyampaikan ide yang telah disepakati dalam kelompoknya kepada guru dan peserta didik lain. Selain itu, tujuan penyampaian ide juga untuk menjaga orisinalitas karya yang akan dibuat dalam penyelesaian masalah. Tahap ke empat yaitu peserta didik membuat rencana penyelesaian proyek. Setelah rencana dibuat, selanjutnya peserta didik dapat memulai proses pengerjaan proyek sesuai jadwal. Paha tahap ini, guru akan bertugas melakukan monitoring terhadap pekerjaan peserta didik. tahap akhir dari model pembelajaran ini adalah menguji hasil proyek yang telah diselesaikan dan mempresentasikannya di depan kelas. Berikut skema kerangka berpikir pada penelitian ini.

\section{METODE PENELITIAN}

Jenis penelitian yang digunakan pada penelitian ini adalah Research and Development (R\&D) model ADDIE. Model ADDIE merupakan model pengembangan yang sederhana dan memiliki pendekatan sistematis dalam menggambarkan bentuk pengembangan. Peneliti memilih model penelitian ADDIE karena produk yang dikembangkan adalah model pembelajaran yang terintegrasi dengan media pembelajaran sehingga model ADDIE dapat digambarkan dengan baik secara rinci sesuai tahapannya.

Berdasarkan pendapat dari Bog and Gall (dalam Togala, 2013, h. 83) Research and Development (R\& D) jenis ADDIE dapat digambarkan dalam bagan berikut ini. 


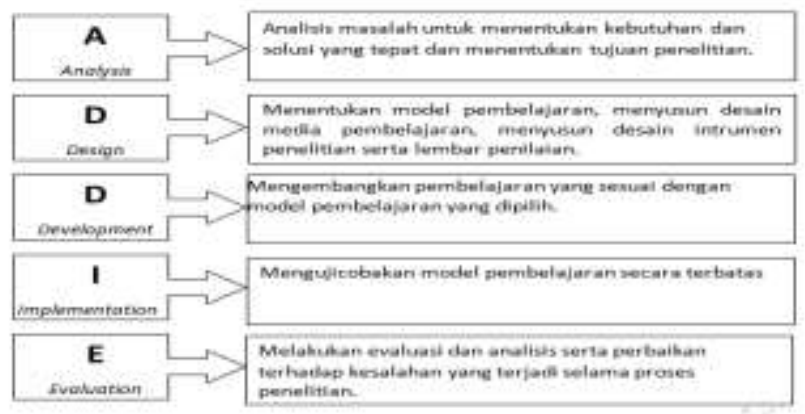

Gambar 1. Desain Penelitian

Dari skema tersebut dapat dijelaskan bahwa Penelitian dan Pengembangan yang diterapkan terbagi menjadi lima tahapan. Tahapan-tahapan tersebut secara rinci akan dijelaskan dengan uraian berikut ini.

\section{Analisis}

Pada tahap analisis terdapat tiga kegiatan. Kegiatan tersebut adalah menganalisis masalah dan menganalisis kebutuhan (needs analyze)(Habibah, Salsabila, Lestari, Andaresta, \& Yulianingsih, 2020). Pada penelitian ini, tahap analisis dilakukan dengan dua tahapan. Tahap pertama adalah menganalisis masalah dan tahap kedua menganalisis kebutuhan (Herliandry, Nurhasanah, Suban, \& Kuswanto, 2020). Pada tahap menganalisis masalah, peneliti melakukan analisis permasalahan dengan rekan sejawat untuk bertukar (sharing) informasi terkait permasalahan yang terjadi (Sefriani, Sepriana, Wijaya, Putra, \& Yptk, 2021). Hasil dari analisis ini yaitu penyebab timbulnya masalah adalah model pembelajaran yang dilakukan guru tidak inovatif. Tahap analisis berikutnya adalah analisis kebutuhan. Hasil analisis kebutuhan yaitu pengembangan Model Pembelajaran Ciri Khusus Hewan menggunakan PBL dan PjBL berbantuan Media Black "Black Box" ARVR.

\section{Design}

Tahap ini juga sering disebut dengan istilah membuat rancangan atau desain produk pengembangan. Desain produk pada tahap ini masih bersifat konseptual yang akan digunakan untuk mendasari tahap pengembangan selanjutnya. Pada tahap desain, dalam penelitian ini peneliti mengembangkan model pembelajaran dalam bentuk purwarupa (prototype) (Cahyani \& Roviati, 2016). Hasil pengembangan tersebut, kemudian dilakukan uji kelayakan dari pakar ahli desain model media pembelajaran (Expert Judgement) (Efendi \& Barkara, 2021). Desain yang dikembangkan akan dilanjutkan apabila mendapatkan predikat layak dari pakar ahli desain model pembelajaran(Harlina, Ramlawati, \& Rusli, 2020).

\section{Development}

Pada tahap Development dalam model ADDIE yaitu kegiatan realisasi pengembangan rancangan produk(Amin, 2017). Pada tahap desain, telah dibuat kerangka konseptual pengembangan Pembelajaran Ciri Khusus Hewan Menggunakan PBL dan PjBL berbantuan Media "Black Box" ARVR(Maulyda, Erfan, \& Hidayati, 2021) Pada Peserta Didik Kelas VI di SD Mandisari. Pada tahap Pengembangan (Development), produk desain yang masih bersifat konseptual tersebut direalisasikan menjadi produk jadi yang siap untuk diimplementasikan(Nafrin \& Hudaidah, 2021). Produk jadi akan dilanjutkan apabila kembali mendapat predikat kelayakan oleh pakar ahli model pembelajaran.

\section{Implementation}

Pada penelitian ini, tahap implementasi dilakukan dilakukan uji coba secara terbatas di luar sampel penelitian, yaitu Kelas V SD Negeri Mandisari(Efendi \& Barkara, 2021). Hasil dari uji coba terbatas kemudian dilakukan evaluasi sebagai pedoman melakukan uji coba pada sampel penelitian yaitu di Kelas VI SD Negeri Mandisari. Setelah implementasi pengembangan Model Pembelajaran Ciri Khusus Hewan Menggunakan PBL dan PjBL berbantuan Media "Black Box" ARVR, kemudian tahap selanjutnya dilakukan 
DOI: https://doi.org/10.31004/basicedu.v6i1.1949

evaluasi awal untuk memperoleh umpan balik (feed back) pada penerapan pengembangan pembelajaran selanjutnya(Irfan, Muhiddin, \& Ristiana, 2019).

\section{Evaluation}

Evaluasi produk pada Penelitian dan Pengembangan pada penelitian ini dilakukan dengan wawancara. Wawancara dilakukan untuk mengetahui tingkat efektivitas produk pengembangan ketika proses implementasi berlangsung (Rusmayanti, Muti'ah, \& Husniah, 2017). Wawancara pada tahap evaluasi dilakukan kepada siswa dan observer pada penerapan produk pengembangan(Wardani, Toenlioe, \& Wedi, 2018). Hasil dari wawancara tersebut kemudian dianalisis untuk dijadikan pertimbangan pada tahapan uji coba secara luas.

Lokasi penelitian ini yaitu Kelas VI SD Negeri se-Kecamatan Parakan, Kabupaten Temanggung. Jumlah sampel pada penelitian ini adalah 22 guru dengan 810 siswa yang dibagi ke dalam dua kelompok kelas. Kelas yang pertama adalah kelas kontrol dan kelas kedua adalah kelas eksperimen. Pembagian kelompok kelas ini didasarkan pada erolehan akreditasi sekolah. Sekolah yang memiliki Akreditasi A menjadi bagian kelas kontrol sedangkan sekolah dengan dengan Akreditasi B menjadi kelas eksperimen. Kelas kontrol merupakan sampel penelitian yang tidak dilakukan implementasi hasil pengembangan dalam proses pembelajarannya, sedangkan kelas eksperimen dalam proses pembelajarannya diterapkan implementasi hasil pengembangan.

\section{HASIL DAN PEMBAHASAN}

Peneliti melakukan kajian teori sebelum mengembangkan model pembelajaran baru. Kajian teori tersebut dilakukan agar model pembelajaran yang dikembangkan tidak menyalahi teori yang sudah ada. Teori yang dirujuk adalah teori Model Pembelajaran PBL dan Teori Model Pembelajaran PjBL. Berikut adalah gambar 2 tentang sintak model PBL dan PjBL(Raihan, 2021).
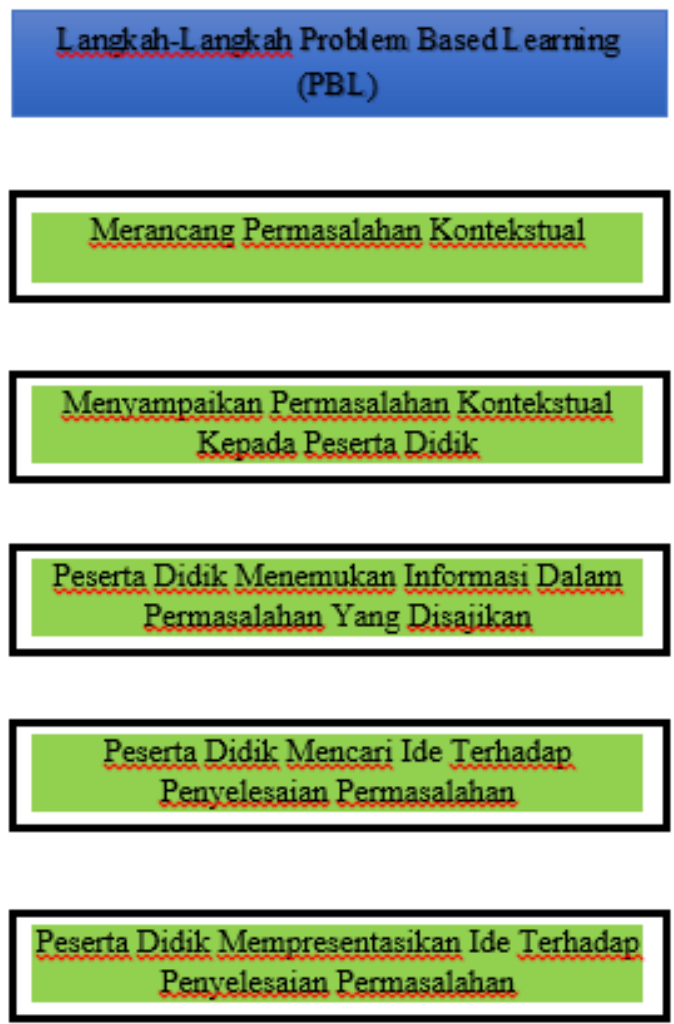

Gambar 2 Sintaks Model Pembelajaran Ciri Khusus Hewan Menggunakan PBL dan PjBL Berbantuan Media Blackbox ARVR
Penyajian Masalah

Perencanaan Pembuatan Produk

Memonitor Produk Yang Dibuat

Uji Coba Produk Yang Dibuat

Evaluasi Produk yang Dibuat 
Hasil belajar peserta didik merupakan data yang digunakan oleh peneliti untuk menguji keberhasilan produk pengembangan yang dilakukan. Hasil belajar diambil dari evaluasi yang dilakukan guru Kelas VI SD Negeri Mandisari pada kelas eksperimen, sedangkan pada kelas Kontrol evalusi langsung dilakukan dengan pemanfaatan Forms Office 365 (Anggrelia, Tarbiyah, Keguruan, Negeri, \& Lampung, 2021). Soal evaluasi yang digunakan sama antara Kelas Kontrol dan Kelas Ekperimen. Hasil evaluasi belajar kemudian dianalisis dan disajikan dalam bentuk tabel 1 dan tabel 2 berikut ini:

Tabel 1 Hasil Belajar Kelas Kontrol

\begin{tabular}{|c|c|c|c|}
\hline NO & Nama Instansi & $\begin{array}{c}\text { Rerata } \\
\text { Nilai }\end{array}$ & Keterangan \\
\hline 1. & SDN Parakan Kauman 1 & 85 & $\mathrm{M}$ \\
\hline 2. & SDN Parakan Kauman 2 & 65 & TM \\
\hline 3. & SDN Parakan Kauman 3 & 70 & $\mathrm{M}$ \\
\hline 4. & SDN Parakan Kauman 6 & 70 & $\mathrm{M}$ \\
\hline 5. & SDN Parakan Wetan 1 & 75 & $\mathrm{M}$ \\
\hline 6. & SDN Parakan Wetan 2 & 70 & $\mathrm{M}$ \\
\hline 7. & SDN Parakan Wetan 3 & 80 & M \\
\hline 8. & SD IT Parakan & 80 & $\mathrm{M}$ \\
\hline 9. & SD Krista Citra & 85 & $\mathrm{M}$ \\
\hline 10. & SD Remaja & 90 & $\mathrm{M}$ \\
\hline 11. & SDN Traji 1 & 90 & $\mathrm{M}$ \\
\hline 12. & SDN Parakan Kauman 1 & 85 & $\mathrm{M}$ \\
\hline 13. & SDN Parakan Kauman 2 & 60 & TM \\
\hline 14. & SDN Parakan Kauman 3 & 80 & $\mathrm{M}$ \\
\hline 15. & SDN Parakan Kauman 6 & 85 & $\mathrm{M}$ \\
\hline & Jumlah & 1170 & \\
\hline & Rentang & 30 & \\
\hline & Rerata & 78 & \\
\hline
\end{tabular}

Dari tabel tersebut, diperoleh data nilai peserta didik pada setiap sekolah dalam kelas kontol cenderung baik karena mencapai ketuntasan klasikal 87\%. Untuk rerata nilai mencapai 78 dengan dua seolah yang tidak mencapai KKM (13\%).

Tabel 2 Hasil Belajar Kelas Eksperimen

\begin{tabular}{clccc}
\hline NO & \multicolumn{1}{c}{ Nama Instansi } & \multicolumn{2}{c}{ Nilai } & Keterangan \\
\cline { 3 - 4 } & & $\begin{array}{c}\text { Sebelum } \\
\text { Peanfaatan }\end{array}$ & $\begin{array}{c}\text { Sesudah } \\
\text { Pemanfaatan }\end{array}$ & \\
\hline 1. & SDN Parakan Kauman 5 & 40 & 75 & $\mathrm{M}$ \\
\hline 2. & SDN Mandisari & 60 & 70 & $\mathrm{M}$ \\
\hline 3. & SDN Bagusan & 40 & 50 & $\mathrm{TM}$ \\
\hline 4. & SDN Dangkel & 45 & 70 & $\mathrm{M}$ \\
\hline 5. & SDN Caturanom & 50 & 75 & $\mathrm{M}$ \\
\hline 6. & SDN Campursalam & 65 & 80 & $\mathrm{M}$ \\
\hline 7. & SDN Glapansari 1 & 60 & 70 & $\mathrm{M}$ \\
\hline 8. & SDN Glapansari 2 & 50 & 80 & $\mathrm{M}$ \\
\hline 9. & SDN Traji 2 & 40 & 75 & $\mathrm{M}$ \\
\hline 10. & SDN Nglondong & 45 & 70 & $\mathrm{TM}$ \\
\hline 11. & SDN Parakan Kauman 5 & 40 & 60 & $\mathrm{M}$ \\
\hline 12. & SDN Mandisari & 50 & 70 & \\
\hline
\end{tabular}



Media Black Box ARVR - Ahmad Irfan Barokah, Hari Wahyono, Sri Listyarini

DOI: https://doi.org/10.31004/basicedu.v6i1.1949

\begin{tabular}{ccccc}
\hline 13. & SDN Bagusan & 55 & 60 & TM \\
\hline 14. & SDN Dangkel & 50 & 70 & $\mathrm{M}$ \\
\hline 15. & SD Sunggingsari & 60 & 80 & $\mathrm{M}$ \\
\hline & Jumlah & 670 & 940 & \\
\hline & Rentang & 45 & 60 & \\
\hline & Rerata & 45 & 73 &
\end{tabular}

Keterangan : TM (tidak memenuhi KKM), M (memenuhi KKM)

Dari tabel tersebut, diperoleh data nilai peserta didik di setiap sekolah pada kelas eksperimen cenderung mengalami peningkatan dari sebelum pemanfaatan pengembangan. Dari tabel tersebut dapat diambil kesimpulan bahwa sebelum penerapan produk pengembangan, nilai hasil belajar peserta didik sebanyak 15 kelas $(100 \%)$ yang berada di kelas eksperimen tidak mencapai KKM atau tidak lulus. Setelah diterapkan produk pengembangan, dari 15 kelas telah mencapai KKM atau ketuntasan sebanyak 12 peserta didik (80\%). Untuk rerata nilai sebelum penerapan produk pengembangan hanya mencapai 45 , sedangkan setelah diterapkan produk pengembangan rerata nilai peserta didik mencapai mencapai 73 .

Tabel 3 Integrasi Nilai Kelas Kontrol dan Kelas Eksperimen

\begin{tabular}{lccc}
\hline \multirow{2}{*}{ Aspek } & \multicolumn{2}{c}{ Kelompok Kelas } & Rasio \\
\cline { 2 - 4 } & Kelas Kontrol & $\begin{array}{c}\text { Kelas } \\
\text { Eksperimen }\end{array}$ & \\
\hline Jumlah & 1170 & 940 & 230 \\
\hline Rerata & 78 & 73 & 15 \\
\hline Persentase Ketuntasan klasikal (\%) & 87 & 80 & 27 \\
\hline
\end{tabular}

Dari tabel 3 tersebut, bahwa produk pengembangan Model Pembelajaran Target belajar dapat diukur melalui perubahan sikap dan kemampuan peserta didik melalui proses belajar, ketercapaian target belajar membuktikan bahwa pembelajaran yang dilakukan telah berhasil (anggi lestari, 2016). Berdasarkan pendapat tersebut, artinya pengembangan Pengembangan Model Pembelajaran Ciri Khusus Hewan Menggunakan PBL dan PjBL berbantuan Media "Black Box" ARVR telah berhasil karena telah mencapai target belajar yaitu $80 \%$ kelas pada kelas eksperimen mencapai ketuntasan belajar.

Setelah produk pengembangan diimplementasikan pada proses pembelajaran di kelas VI SD Negeri Mandisari, terdapat saran-saran dari observer. Saran-saran tersebut dijadikan dasar pagi pengembang untuk mengevaluasi produk pengembangan sehingga dapat digunatakan secara luas. Berikut evaluasi dan rekomendasi produk pengembangan Pengembangan Model Pembelajaran Ciri Khusus Hewan Menggunakan PBL dan PjBL berbantuan Media "Black Box" ARVR.

1. Dibuat buku panduan manual yang lebih rinci agar pengguna dengan mudah menggunakan produk pengembangan.

2. Diseminasikan produk pengembangan secara luas dan diujicobakan secara luas pula.

3. Perlu dibuat versi yang lebih komplek sampai seratus angka dalam permainan agar lebih menantang peserta didik.

4. Masukkan ke dalam aplikasi google playstore atau appstore agar mudah didapatkan masyarakat secara umum.

5. Soal-soal dalam permainan disederhanakan, karena sifatnya meningkatkan minat peserta didik. 


\section{KESIMPULAN}

Hasil pengembangan Model Pembelajaran Ciri Khusus Hewan Menggunakan PBL dan PjBL berbantuan Media Black "Black Box" ARVR dikembangkan berdasarkan saran yang diterima oleh peneliti dari pakar-pakar ketika proses pembuatan desain produk. Atas saran tersebut, kemudian peneliti melakukan pengembangan desain menjadi produk jadi. Hasil produk pengembangan juga telah divalidasi kembali oleh expert yang sama pada proses pengembangan desain. Dari hasil implementasi pengembangan yang dilakukan di Kelas VI SD negeri Mandisari dengan model kelas kontrol dan kelas eksperimen. Hasil dari proses implementasi menyimpulkan bahwa pengembangan Model Pembelajaran Ciri Khusus Hewan Menggunakan PBL dan PjBL berbantuan Media Black "Black Box" ARVR dapat meningkatkan minat dan hasil belajar peserta didik.

\section{DAFTAR PUSTAKA}

Amin, A. K. (2017). Kajian Konseptual Model Pembelajaran Blended Learning Berbasis Web Untuk Meningkatkan Hasil Belajar Dan Motivasi Belajar. Jurnal Pendidikan Edutama, 4(2), 51-64.

Anazifa, R. D., \& Djukri. (2017). Project- Based Learning And Problem- Based Learning: Are They Effective To Improve Student's Thinking Skills? Jurnal Pendidikan Ipa Indonesia, 6(2), 346-355. Https://Doi.Org/10.15294/Jpii.V6i2.11100

Anggi Lestari. (2016). Penerapan Strategi Pembelajaran Kontekstual Untuk Meningkatkan Kemampuan Berpikir Kritis Matematika. Jurnal Ilmu Pendidikan, 22(1), 9-17. Retrieved From Http://Journal.Um.Ac.Id/Index.Php/Jip/Article/View/8639

Anggrelia, T., Tarbiyah, F., Keguruan, D. A. N., Negeri, U. I., \& Lampung, R. I. (2021). Pengembangan Media Pembelajaran Pada Pembelajaran Tematik Tema 8 Pada Pembelajaran.

Cahyani, D., \& Roviati, E. (2016). Penerapan Pembelajaran Ipa Berbasis Keterampilan Proses Sains Untuk Meningkatkan Literasi Sains Pada Mata Pelajaran Ipa Di Kelas Vii Materi Pokok Pencemaran Lingkungan Di Smpn 1 Cikijing. Jurnal Sains Dan Pendidikan Sainspd.I; Jurusan Tadris Ipa Biologi Jalan Perjuangan Bypass Sunyaragi Cirebon, 5(45132), 122-135. Retrieved From Www.Syekhnurjati.Ac.Di/Jurnal/Index.Php/Sceducatia

Dolmans, D. H. J. M., Loyens, S. M. M., Marcq, H., \& Gijbels, D. (2016). Deep And Surface Learning In Problem-Based Learning: A Review Of The Literature. Advances In Health Sciences Education, 21(5), 1087-1112. Https://Doi.Org/10.1007/S10459-015-9645-6

Education, E., Fadil, K., Kurnia, D., Ibn, U., Bogor, K., Barat, J., ... Barat, J. (2021). Jurnal Basicedu, 5(1), $19-29$.

Efendi, N., \& Barkara, R. S. (2021). Studi Literatur Literasi Sains Di Sekolah Dasar. Jurnal Dharma Pgsd, 1(2), 57-64. Retrieved From Http://Ejournal.Undhari.Ac.Id/Index.Php/Judha/Article/View/193

Habibah, R., Salsabila, U. H., Lestari, W. M., Andaresta, O., \& Yulianingsih, D. (2020). Pemanfaatan Teknologi Media Pembelajaran Di Masa Pandemi Covid-19. Trapsila: Jurnal Pendidikan Dasar, 2(02), 1. Https://Doi.Org/10.30742/Tpd.V2i2.1070

Harlina, H., Ramlawati, R., \& Rusli, M. A. (2020). Deskripsi Kemampuan Literasi Sains Peserta Didik Kelas Ix Di Smpn 3 Makassar. Jurnal Ipa Terpadu, 3(2), 96-107. Https://Doi.Org/10.35580/Ipaterpadu.V3i2.12320

Herliandry, L. D., Nurhasanah, N., Suban, M. E., \& Kuswanto, H. (2020). Pembelajaran Pada Masa Pandemi Covid-19. Jtp - Jurnal Teknologi Pendidikan, 22(1), 65-70. Https://Doi.Org/10.21009/Jtp.V22i1.15286

Irfan, I., Muhiddin, M., \& Ristiana, E. (2019). Pengembangan Media Pembelajaran Ipa Berbasis Powerpoint Di Sekolah Dasar [Powerpoint-Based Science Learning Media Development In Elementary Schools]. Indonesian Journal Of Primary Education, 3(2), 16-27. 

Media Black Box ARVR - Ahmad Irfan Barokah, Hari Wahyono, Sri Listyarini DOI: https://doi.org/10.31004/basicedu.v6i1.1949

Maulyda, M. A., Erfan, M., \& Hidayati, V. R. (2021). Analisis Situasi Pembelajaran Selama Pandemi Covid19 Di Sdn Senurus: Kemungkinan Terjadinya Learning Loss. Collase, 04(03), 328-336.

Nafiah, Y. N., Suyanto, W., \& Yogyakarta, U. N. (2014). Penerapan Model Problem-Based Learning Untuk Meningkatkan Keterampilan Berpikir Kritis Dan The Application Of The Problem-Based Learning Model To Improve The Students Critical Thinking. Jurnal Pendidikan Vokasi, 4, Nomor 1(C), 125-143.

Nafrin, I. A., \& Hudaidah, H. (2021). Perkembangan Pendidikan Indonesia Di Masa Pandemi Covid-19. Edukatif: Jurnal Ilmu Pendidikan, 3(2), 456-462. Https://Doi.Org/10.31004/Edukatif.V3i2.324

Raihan, S. (2021). Implementasi Workshop Blended Learning Menggunakan E-Book Lesson Plan Berbasis Hypercontent Dalam Meningkatkan Kompetensi Guru. Publikasi Pendidikan, 11(1), 57. Https://Doi.Org/10.26858/Publikan.V11i1.19075

Rusmayanti, A., Muti'ah, A., \& Husniah, F. (2017). Penerapan Keterampilan Bertanya Dan Memberikan Penguatan Dalam Pembelajaran Bahasa Indonesia Di Kelas Vii Smp Negeri 4 Jember. Lingua Franca, Vol. Ii (2(2), 510-518.

Sefriani, R., Sepriana, R., Wijaya, I., Putra, U., \& Yptk, I. (2021). Edukatif: Jurnal Ilmu Pendidikan Efektivitas Pembelajaran Online Di Masa Pandemi Covid-19, 3(6), 4731-4737.

Siagian, G. (2021). Jurnal Basicedu. Jurnal Basicedu, 5(3), 1683-1688.

Siswa, B. M., \& Ammy, P. M. (2021). Jurnal Basicedu, 5(5), 3242-3249.

Utia, R., \& Fauzi, A. (2021). The Validity Of The Integrated Physics Ebook On Landslide Disaster Mitigation Materials Based On A Problem Based Learning Model. International Journal Of Progressive Sciences And Technologies, 25(1), 630. Https://Doi.Org/10.52155/Ijpsat.V25.1.2731

Wardani, D. N., Toenlioe, A. J. E., \& Wedi, A. (2018). Daya Tarik Pembelajaran Di Era 21 Dengan Blended Learning. Jurnal Kajian Teknologi Pendidikan (Jktp), 1(1), 13-18. Retrieved From Https://Core.Ac.Uk/Download/Pdf/287323676.Pdf 